UNIVERSIDADE REGIONAL DO CARIRI, URCA

PRO-REITORIA DE ENSINO DE GRADUAÇÃO- PROGRAD

CURSO DE LICENCIATURA NO ENSINO MÉDIO COM HABILIDADE EM LÍNGUA PORTUGUESA E INGLESA

LINGUÍSTICA NA SALA DE AULA: DISTORÇÕES ENTRE DISCURSOS E PRÁTICAS NA INSTITUIÇÃO ESCOLAR:

E.E.E.I.F.M SANTA MARIA GORETE

IZABEL MARIA DE MATOS 
OUTUBRO- 2009

IZABEL MARIA DE MATOS

\section{LINGUÍSTICA NA SALA DE AULA: DISTORÇÕES ENTRE DISCURSOS E PRÁTICAS NA INSTITUIÇÃO ESCOLAR: E.E.E.I.F.M SANTA MARIA GORETE}

Trabalho Monográfico conclusivo apresentado como requisito parcial para obtenção do título do Curso Licenciatura em Língua Portuguesa e Inglesa orientado pelo Professor Mauro César Alves.

SÃO JOSÉ DE PIRANHAS -PB

OUTUBRO - 2009 
UNIVERSIDADE REGIONAL DO CARIRI, URCA PRO-REITORIA DE ENSINO DE GRADUAÇÃO - PROGRAD CURSO DE LICENCIATURA NO ENSINO MÉDIO COM HABILIDADE EM LÍNGUA PORTUGUESA E INGLESA AUTORA: IZABEL MARIA DE MATOS

LINGUÍSTICA NA SALA DE AULA: DISTORÇÕES ENTRE DISCURSOS E PRÁTICAS NA INSTITUIÇÃO ESCOLAR:

E.E.E.I.F.M SANTA MARIA GORETE

BANCA EXAMINADORA:

$1^{\circ}$

ORIENTADOR

$2^{\circ}$

COORDENAÇÃO

CONCEITO 


\section{DEDICATÓRIA}

Ao meu Deus que tem me ensinado que para todo propósito há tempo e modo. 


\section{AGRADECIMENTOS}

Meus sinceros agradecimentos a todos aqueles que de alguma forma doaram um pouco de si para que a conclusão deste trabalho se tornasse possível.

A Deus, por acreditar que minha existência pressupõe uma outra infinitamente superior.

Aos meus pais, pelo exemplo, amizade e o carinho.

Ao professor orientador, pelo auxílio e disponibilidade. 
A linguagem é o instrumento graças ao qual o homem modela seu pensamento, seus sentimentos, suas emoções, seus esforços, sua vontade e seus atos, o instrumento graças ao qual ele influencia e é influenciado, a base última e mais profunda da sociedade humana.

Hjelmslev 


\section{RESUMO}

Propostas de (ré) elaboração de práticas coletivas em favor da dinamização dos usos da linguagem são lançadas e é nesta perspectiva que se vislumbra a possibilidade de serem alargadas as correntes em que se configura nossa preocupação maior. Sob esse prisma, estão os professores de língua materna do Ensino Fundamental - 1a fase da E.E.E.F.M. Santa Maria Gorete, da cidade de São José de Piranhas - PB possuem educação linguística adequada para abordá-la como instrumento de (ré) vitalização das práticas de língua materna?Os alunos dos cursos de Letras não são mais os mesmos, a desvalorização da profissão docente e os baixos salários atraem alunos advindos de contextos com práticas precárias de leitura e de produção textual. No entanto, esses cursos ainda permanecem presos as suas "grades curriculares", preocupadas com a reprodução e acumulação do saber.Outro ponto a ser questionado é a formação continuada dos professores, oferecida pêlos governos e que são marcadas pela desarticulação e descontinuidade, principalmente em virtude das mudanças de plano a cada troca de governo. Os professores estão diante de um novo desafio, novos paradigmas são elaborados para essas mudanças? Eles compreendem crítica e teoricamente o que a eles é "proposto" como parâmetro? A sua formação possibilitou sua autonomia para efetivar esse trabalho em sala de aula? Essas reflexões aliadas às perguntas de pesquisa apresentadas anteriormente, nos levaram a outra realidade: a sala de aula. Diante disso, questionamos a formação, tanto inicial como continuada, pautada sempre pela prática reflexiva por parte do professor, amparada por uma estrutura institucional que possibilite essa reflexão. É fundamental que esses programas de formação tenham como objetivo promover a educação e não as ações de um determinado governo, de forma que sejam articulados, contínuos e que ofereçam aos professores não modelos e receitas, mas principalmente, suporte teórico para que possam fundamentar sua ação docente e refletir sobre sua prática na sala de aula.

Palavras-chave: linguagem, educação lingüística, ação e reflexão. 


\begin{abstract}
Proposed of (ré) elaboration of collective practices in favor of the dinamização of the uses of the language is launched and it is in this perspective that is shimmered the possibility of the currents they be enlarged in that our larger concern is configured.Under that prism, are the teachers of maternal language of the Fundamental Teaching - 1a phase of E.E.E.F.M. Santa Maria Gorete, of the city of São José of Piranhas - do PB possess appropriate linguistic education to approach her as instrument of (ré) vitalização of the practices of maternal language? The students of the courses of Letters are not more the same ones, the depreciation of the educational profession and the low wages attract students advindos of contexts with precarious practices of reading and of textual production. However, those courses still stay arrested your " grating curriculares ", concerned with the reproduction and accumulation of the knowledge. Another point to be questioned is the teachers' continuous formation, offered hair governments and that they are marked by the desarticulação and descontinuidade, mainly by virtue of the plan changes to each government change. Are the teachers before a new challenge, are new paradigms elaborated for those changes? Do they understand critic and theoretically the one what to them is as parameter proposed "? Did your formation make possible your autonomy to execute that work in class room? Those allied reflections to the research questions presented previously, they took us the other reality: the room of aula.Diante of that, we questioned the formation, as much initial as continuous, always ruled by the reflexive practice on the part of the teacher, aided by an institutional structure that makes possible that reflection. It is fundamental that those formation programs have as objective promotes the education and not a certain government's actions, so that they are articulate, continuous and that they offer to the teachers non models and revenues, but mainly, support theoretical so that they can base your educational action and to contemplate on your practice in the class room.
\end{abstract}

Key word: language, linguistic education, action and reflection. 


\section{SUMÁRIO}

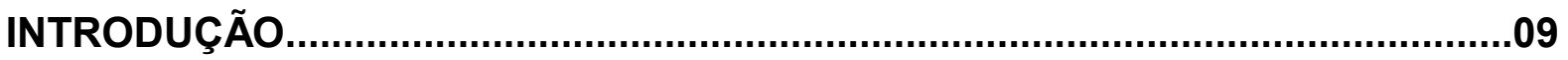

1 - LINGUAGEM E ESCOLA: A ( DES) CONSTRUÇÃO DA LINGUÍSTICA.............12

2- LINGUÍSTICA: OBJETOS CONCEITOS E PRESSUPOSTOS................................17

2.1- A utilização da leitura e escrita na língua materna como uma tarefa multidisciplinar.....19

3 - A PRÁTICA DE REFLEXÃO SOBRE O LUGAR DO TEXTO E DA GRAMÁTICA NA SALA DE AULA NAS PRÁTICAS LINGUISTICAS..............................................26

4-ABORDAGEM DIDÁTICO-PEDAGÓGICA QUANTO ÀS SEMELHANÇAS E DIFERENÇAS NO PROCESSO DE ENSINO -APRENDIZAGEM DA LÍNGUA MATERNA...............................................................................................................................30

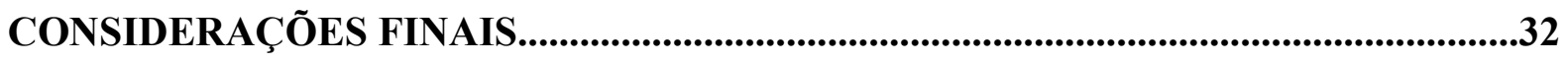

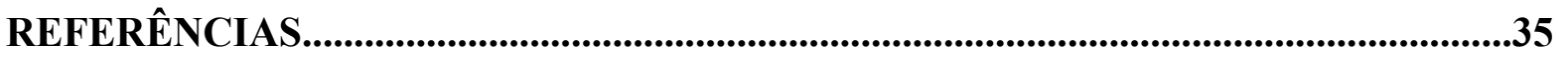




\section{INTRODUÇÃO}

Dentre as características que nos diferenciam de todas as outras espécies, a capacidade que possuímos de interagir no meio social através da expressão verbal parece ser a mais notável de todas, pois é justamente esta habilidade que torna possível ultrapassarmos os limites da inteligência sensório motora, evocarmos situações passadas e nos libertarmos das fronteiras do espaço próximo e imediato, interagindo, assim, com outros interlocutores na coconstrução do conhecimento.

Portanto, não é de todo estranho que tenhamos buscado, desde a antiguidade, saber mais sobre esta habilidade inerente ao ser humano. Assim, é possível encontrar a linguagem verbal como objeto de estudo tanto nas Ciências Naturais, Humanas e Sociais. Nos domínios da Biologia e da Medicina, por exemplo, o interesse é por estudos que focalizam a anatomia e o funcionamento do aparelho fonador, o cérebro e as áreas relacionadas com a produção da língua e as patologias associadas à produção e processamento da fala e do processamento linguístico. A Psicologia, por sua vez, procura entender outras facetas da linguagem tais como a forma pela qual se processa o desenvolvimento desta e do pensamento humano através da cognição, investigado, também, as causas e possíveis tratamentos de patologias como a afasia ou a dislexia. Outra área acadêmica que desenvolve estudos relacionados à linguagem é a Sociologia, descrevendo e buscando entender como a visão de mundo de um grupo social é construída e representada através dos signos linguísticos por ele adotados.

Já a Linguística, dentro de seus múltiplos campos de investigação, pode fazer um estudo sistemático de uma dada língua, descrevendo as suas unidades mínimas, por exemplo. Além destas disciplinas, encontramos um campo de estudos mais recente, surgido provavelmente entre as décadas de 40 e 50, que também pretende investigar questões referentes à utilização da linguagem. Esta nova área, chamada Linguística Aplicada, é definida por BRUMFIT (1995) como "investigação empírica e teórica de problemas do mundo real nos quais a linguagem é uma questão central". Para tanto, a Linguística Aplicada faz uso não somente dos conhecimentos teóricos produzidos pela Linguística, mas, acima de tudo, dialoga com as descobertas de uma variedade de campos tais como a Antropologia, a Teoria Educacional, a Psicologia e a Sociologia, entre outros, para atingir os seus objetivos, mantendo, assim, uma forte característica multidisciplinar.

A LA como área de conhecimento é vista hoje como articuladora de múltiplos domínios do saber, em diálogo constante com vários campos que têm preocupação com a 
linguagem. Tendo em vista que a linguagem permeia todos os setores de nossa vida social, política educacional e econômica, uma vez que é construída pelo contexto social e desempenha o papel instrumental na construção dos contextos sociais nos quais vivemos, está implícita a importância da LA no equacionamento de problemas de ordem educacional, social, política e até econômica.

Partimos do embasamento de alguns autores como BAGNO (1997-98), BECHARA (2002),GERALDI (2000), LUFT (1995), PEREIRA (2000), como também abordamos a linha de pensamento dos PCNs 97-98que demonstra uma preocupação com a noção de gêneros discursivos, possibilitaria a discussão/ produção de textos de maneira a dar espaços às diferentes vozes que emergem em uma sala de aula, entendidas como representativas de realidades sócio-históricos, distintas e que devem ser vistas e representadas.

De acordo com a preocupação vigente desde os PCNs até o corrente trabalho com a distorção entre discursos e práticas na sala de aula em relação a lingüística aplicada trabalhamos os três capítulo divididos da seguinte forma:

No primeiro capítulo -(1)-Linguagem e Escola: A ( des) construção da linguística, enfatiza a relação educacional materna tendo o professor como eixo central de propagação de uma construção ou desconstrução da linguística; No (2) - Linguística: objetos conceitos e pressupostos e (2.1)- A utilização da leitura e escrita na língua materna como uma tarefa multidisciplina,. visa o exercício da educação linguística, com base na ciência Linguística Moderna. Salienta-se que a escolha deste ou daquele posicionamento em sala de aula decorre em modos distintos de atuação do educador., este com base principalmente nos PCNs abordamos no terceiro capítulo (3)- A prática de reflexão sobre o lugar do texto e da gramática na sala de aula nas práticas lingüísticas, onde aponta um movimento metodológico que vai da AÇÃO e REFLEXÃO que possibilitam ao aluno desenvolver nessa prática a expressão oral e escrita, através de textos, produção de textos orais e escritos e prática de análise linguística. No ultimo capítulo faz-se menção a (4)-Abordagem didáticopedagógica quanto às semelhanças e diferenças no processo de ensino -aprendizagem da língua materna, que todo o sistema educacional oferece até a instituição em questão. No que tange ao sistema educacional brasileiro, a educação linguística orienta para uma reforma do currículo e das atividades pedagógicas, visando, pois, o enriquecimento da competência comunicativa do corpo discente. Nessa perspectiva, a tarefa do professor, em particular o professor de língua materna, é de extrema importância concernente à execução de uma política de educação linguística, visto que cabe à equipe docente oferecer subsídios para uma análise crítico-reflexiva que beneficie o enriquecimento cultural dos educandos. 


\section{1 - LINGUAGEM E ESCOLA: A ( DES) CONSTRUÇÃO DA LINGUÍSTICA}

Destacar a linguagem como instrumento necessário à democratização da sociedade e, por conseguinte da escola é tarefa que se faz urgente.

A língua concebida como meio de integração social, requer entre vários autores a defesa de suas variações, sem ignorar a importância do domínio da norma lingüística. Não podemos fechar os olhos à realidade lingüística: a variedade. Toda variedade tem uma regularidade, não é um caos.

A escola deve respeitar as variações lingüísticas que o aluno usa para interagir, mas também deve ensinar a norma padrão, já que a maioria dos alunos das escolas públicas não têm acesso a este tipo de linguagem. A norma padrão culta não deve ser ensinada como uma imposição da classe dominante, nem como uma possibilidade de ascensão social, mas com outro objetivo, que é o falante ter competência para se expressar através da variante padrão da Língua Portuguesa, explicando-lhe como e em quais lugares ou ambientes usá-la. De acordo com BAGNO (1997):

O objetivo da escola, no que diz respeito à língua, é formar cidadãos capazes de se exprimir de modo adequado e competente, oralmente e por escrito, para que possam se inserir de pleno direito na sociedade e ajudar na construção e na transformação dessa sociedade.

Também é necessário conduzir de uma melhor forma o ensino da norma-padrão. Está ultrapassado trabalhar o português através de "erros" e "acertos", "isto pode" ou "isto não pode" As diferenças lingüísticas não devem ser vistas como deficiências lingüísticas.

A língua-padrão deve ser ensinada mostrando ao aluno que há variações em uma comunidade, que ocorrem em função do contexto em que são empregadas.

Oferecer alternativas de valoração da linguística dentro do contexto dos cursos de formação de professores é também destacar a importância de se abordar a língua materna numa visão ampla, como elemento de comunicação e expressão. Entretanto, principalmente no âmbito da escola, cuja função deveria ser a estimulação sociocultural do individuo pelas práticas interlocutivas, imposto pela sociedade e referendado pelo contexto escolar que aborda a língua sobre ângulos utilitaristas e preconceitos dissociados da realidade sóciocognitiva do aluno. 
Essas constatações, embora generalizadas, remetem ao fato de que, atualmente, diversos estudos anunciam uma crise no diversos estudos anunciam uma crise no ensino de língua portuguesa, sobretudo nos patamares do ensino fundamental e médio, bases para toda a vida acadêmica do indivíduo. Significa dizer que os desafios impostos pela sociedade atual têm requerido um domínio mais efetivo da linguagem e da língua, imprescindível como mediação aos atos de conhecer o mundo.

O mais grave é que a realidade de nosso sistema educacional tem deixado à mostra graves seqüelas no que se refere ao ensino da língua materna e o problema desenvolve numa proporção que envolve professor e alunos, sendo o primeiro, o eixo central dessa problemática. Empenhados na superação desses problemas, surgem no seio, dos cursos de formação de professores, sobretudo no ensino superior (embora, ainda de forma embrionária), diversos grupos e correntes de trabalho preocupados em assegurar que a língua portuguesa seja aborda, não sob um prisma utilitarista, mas como efetivo instrumento de dialogicidade de sujeitos e, por conseguinte, viva, dinâmica, servindo como um efetivo meio de transformação. A figura do professor é essencial. Sob hipótese alguma, ele poderá esconder-se atrás dos livros didáticos, expondo repetidamente regras e definições isentas de quaisquer análise e reflexão crítica. Como reforçam as palavras de PEREIRA (2000):

Deve ser crítico e fazer com que seus alunos (com as adequações compativeis ao nível) exerçam o sentido da crítica, conhecendo teorias diversas, sem medo de ser avançado (ousado) demais ou tradicional (antigo, ultrapassado), lembrando-se de que como usuário da língua (para comunicar-se simplesmente ou fazer uso de sua função expressiva, estética), ele tem direitos e deveres, não sendo indiferente, alheio, neutro. Muito menos temer alguma pergunta embaraçosa que não possa responder correta e imediatamente.

Dessa maneira, cabe ao docente dialogar com os alunos na língua e sobre a língua, interagindo social e linguisticamente.

A constatação de que é uma perda de tempo reduzir as aulas da disciplina da língua portuguesa, sobretudo, no ensino fundamental, a meros exercícios de " gramatiquês", é motivo para se alertar os professores que, preocupados em cumprir programas inexeqüíveis, julgam que deixando de ensinar a gramática prescrita, pura e simplesmente, nada têm a fazer em sala de aula. Primeiramente, é oportuno elucidar que gramática distingue se de linguística, visto que esta é uma ciência da linguagem. Já aquela constitui uma doutrina, isto é, uma tentativa não-científica de explicar os fenômenos da língua. O estudioso BECHARA (2002) ratifica que: 
A gramática não se confunde com a linguística, tendo em vista os próprios objetivos de cada uma. Enquanto a primeira, normativa, registra o uso idiomático da modalidade-padrão, a segunda, como ciência, estuda a linguagem articulada nos seus polifacetados aspectos e realizações.

Se esses professores, realmente tomarem consciência da importância dessa forma de ensino, pode ser comprovado pelo péssimo desempenho lingüístico de grande parte dos professores de nossas escolas, comprovados pela falta de habilidade com a língua portuguesa nos níveis fundamental e médio, hão de acatar sugestões de mudanças e, a partir do conhecimento da realidade do aluno, ousarão aplicar novas alternativas teórico-metodológicas que releguem a gramática puramente prescrita um ensino que se pauta na praticidade, na crítica e na criatividade. Enfim, como muito bem lembra PEREIRA (2000):

Dá muito trabalho ser bom e eficiente professor de Língua Portuguesa. Títulos, cursos, leituras, eventos, ajudam - e muito. Entretanto, o mais importante é o entusiasmo, a paixão (gostamos dessa palavra) por aquilo que se faz, acreditar que se é capaz, pelo menos, de mudar aquela turma, as pessoas que estão ali, naquele momento, em algumas horas, em um semestre, em um ano, porque naquele breve tempo poderá, além de ensinar, "despertar" o desejo por mais, "instigar" a procura do conhecimento, ser responsável pelo aparecimento de pessoas especiais.

Sob a ótica de LUFT (1995), para uma tentativa de mudança no ensino de língua materna, alguns pressupostos são pertinentes.Segundo o autor faz-se necessário que o professor tenha competência para:

- Descobrir a gramática que o aluno internalizou que se liga, diretamente a realidade sociocultural de cada individuo;

- Valorizar as estruturas lingüísticas que o aluno constrói, incentivando-o par a efetiva utilização e desenvolvimento da língua oral;

- Capacitar o aluno para construir enunciado e opinar entre várias possibilidades dialógicas as que melhor servem para as suas práticas comunicativas;

- Realizar atividades e variabilidade expressional, paráfrases, transformações (re) laboradas de enunciados.

Procurando ampliar a gramática implica que o aluno interiorizou no primeiro ciclo do ensino fundamental com os elementos próprios do modelo dito padrão e colocando-o em contato com bons materiais, de linguagem, a fim de que ele descubra as possibilidades expressionais de seu idioma, o professor terá atingido o objetivo precípuo do ensino de língua materna: favorecer um melhor desempenho do individuo na comunicação oral e escrita e, por 
seguintes a efetivação de práticas sociais e culturais críticas e criativas.Essas possibilidades desenvolvem significadamente no combate ao preconceito linguístico.

E evidente que uma prática docente de qualidade aliada a um ensino efetivo de língua e linguagem não depende da apresentação de manuais com receitas pré-fabricadas, sobretudo, porque cada sujeito tem sua historia de vida, com aptidões pessoais defendida e, além disso, insere-se nessa historia pessoal a realidade lingüística e, por conseguinte, a realidade social do individuo.

Justificar-se, portanto, a necessidade que a formação de professores seja pautada na observância dessas características particulares, que carece de subsídios teóricos metodológicos que abarquem as dimensões linguísticos- sociais de cada um, capazes de favorecer o desenvolvimento do professor- pesquisador tão requerido nos dias atuais. Esse modelo de professor é delineado por NACARDTO ( in Geraldi, 2000):

[...] é o docente que questiona e resiste a racionalidade técnica e reflete criticamente sobre prática docente. E aquele que apesar de todas as tentativas externas de limitações do seu trabalho volta o seu olhar ao (á) aluno (a), tratando(a) respeitosamente. Como um sujeito histórico e inserido num contexto social. E aquele que tenta " driblar "as limitações e buscar desenvolver, com o coletivo da escola projetos de trabalho docente.

Esse modelo de docente é requerido pelos Parâmetros Curriculares Nacionais- PCNs -que, em linha gerais propõem-se a subsidiar a elaboração e/ ou revisão curricular em instituição subsidiar a elaboração e/ ou revisão curricular em instituições educacionais de Estados e Municípios, incentivando a discussão pedagógica interna nas escolas e a elaboração de projetos educativos, além de servir de material reflexivo para a prática docente. Os Parâmetros Curriculares Nacionais de Língua Portuguesa (doravante PCNs), publicados em 1998, incorporam as idéias linguísticas previstas para o ensino de língua materna. Segundo os PCN, no Ensino Fundamental, espera-se:

Que o aluno amplie o domínio ativo do discurso nas diversas situações comunicativas, sobretudo nas instâncias públicas de uso da linguagem, de modo a possibilitar sua inserção efetiva no mundo da escrita, ampliando suas possibilidades de participação social no exercício da cidadania (PCN 1998 apud Pisciotta, 2001, ).

Especificamente, no caso do ensino de língua portuguesa, os PCNs (1997) objetivam: "[...] garantir aos alunos o acesso aos saberes linguísticos, necessários para o exercício de cidadania, direito inalienável de todos.” 
Dentro das exigências dos PCNs inserem-se; a necessidade de formação da competência gramatical ou linguística e da competência textual, que abarca a capacidade formativa, a capacidade transformativa e a capacidade qualificativa dos usuários da língua materna.

Uma prática institucional que toma como referencial esses pressupostos, sugere a formação de núcleos e grupos de estudos, sobretudo na Universidade, nos campos de ensino, pesquisa e extensão, que abordem a lingüística num enfoque interdisciplinar, centrados em ramos que transitem da psicologia à sociologia, passando por outras áreas do conhecimento e convergindo para o campo de ciências da linguagem. 


\section{2- LINGUÍSTICA: OBJETOS CONCEITOS E PRESSUPOSTOS}

Toda a análise sociolinguística a ser orientada para as variações sistemáticas, inerentes ao seu objeto de estudo a comunidade de fala, concebidas como uma heterogeneidade estruturada. Não existe, portanto um caos linguístico, cujo processamento, análise e sistematização sejam impossíveis de serem processados Há, pelo contrário, um sistema (uma organização) por trás da heterogeneidade da língua falada.

A Sociolínguística tem por objeto de estudo os padrões de comportamento linguístico observáveis dentro de uma comunidade de fala e os formaliza analiticamente através de um sistema heterogêneo, constituído por unidades e regras variáveis. Esse modelo visa a responder a questão central da mudança linguística a parir de dois principios teóricos fundamentais: (I) o sistema linguístico que serve a uma comunidade plural deve ser também heterogêneo e plural para desempenhar plenamente as suas funções; rompendo-se assim a tradicional identificação entre funcionalidade e homogeneidade; (II) os processos de mudança que se verificam em uma comunidade de fala se atualizam na variação observada em cada momento nos padrões de comportamento linguístico observados nessa comunidade, sendo que, se a mudança implica necessariamente variação, a variação não implica necessariamente mudança em curso.

Um estudo sociolinguístico visa á descrição estatisticamente fundamentada de um fenômeno variável, tendo como objetivo analisar, apreender e sistematizar variantes linguísticas usadas por uma mesma comunidade de fala Para tanto, calcula-se a influencia que cada fator, interno ou externo ao sistema linguístico, possui na realização de uma ou da outra variante. Ao formalizar esse cenário, a análise sociolingüística busca estabelecer a relação entra o processo de variação que se observa na língua em um determinado momento (isto é. sincronicamente) com os processos de mudança que estão acontecendo na estrutura da língua ao longo do tempo (isto é, diacronicamente).

A possibilidade de se fazer inferências acerca do desenvolvimento diacrônico da língua a partir de análises sincrônicas ganhou corpo na pesquisa linguística com os estudos desenvolvidos por Wlliam Labov na década de 1960 primeiramente na ilha de Martha's Vineyard. em 1963, e depois na cidade de Nova York, em 1966. Como afirmaria o próprio Labov (1972). concebendo a variação linguística como um fenômeno sistemático, e não aleatório, através da correlação entre fatores linguísticos e fatores sociais, poder-se-ia superar a barreira erguida por HOCKETT (1958), "e acerta entre os estruturalistas americanos, de que 
a mudança linguística não podem ser observada em seu processo de implementação, mas apenas em seus resultados finais". Fundamentalmente, postula-se que a variação observada sincronicamente em um determinado ponto da estrutura da gramática de uma comunidade de fala pode refletir um processo de mudança em curso na língua, no plano diacrônico. Desse modo, busca-se apreender o tempo real onde se dá desenvolvimento diacrônico da língua, no chamado tempo aparente. O tempo aparente constitui, assim, uma espécie de projeção.

O pressuposto central do tempo aparente é o de que as diferenças no comportamento linguístico de gerações diferentes de falantes num determinado momento refletiriam diferentes estágios do desenvolvimento histórico da língua.

Pondo de maneira simples e direta, podemos dizer que o objeto da Sociolinguística é o estudo da língua falada, observada, descrita e analisada em seu contexto social, isto é, em situações reais de uso.

O ponto de partida da sociolingüística e psicolingüística é a comunidade lingüística, um conjunto de pessoa que interagem verbalmente e que compartilham um conjunto de normas com respeito aos usos linguísticos.

A depender do alcance e dos objetos de um trabalho de natureza sociolingüística, podemos selecionar e descrever muitas comunidades de fala. Ao estudar qualquer comunidade lingüística, a constatação mais imediata é a existência de diversidade ou da variação. Isto é, toda comunidade se caracteriza pelo emprego de diferentes modos de falar. A essas diferentes maneiras de dar, a sociolingüística atribui o nome de variedades linguísticas.

Conforme GERALDI (1984) afirma a respeito de ensino e metalinguagem:

Parece-me que o mais caótico da atual situação de ensino de língua portuguesa nas escolas de primeiro grau consiste precisamente no ensino, para alunos que sequer dominam a variedade culta, de uma metalinguagem de análise desta variedade, com exercícios contínuos de descrição gramatical, estudo de regras e hipóteses de análise de problemas que mesmo especialistas não estão seguros de como resolver.

O autor critica o ensino onde são dadas muitas páginas de tempos e modos verbais, sem o aluno ter a compreensão do significado do que está estudando. Continua GERALDI (1984):

[...] uma coisa é saber a língua, isto é, dominar as habilidades de uso da língua em situações concretas de interação, entendendo e produzindo enunciados, percebendo as diferenças entre uma forma de expressão e outra. Outra coisa é saber analisar uma língua dominando conceitos e metalinguagens a partir dos quais se fala sobre a língua, se apresentam suas características estruturais e de uso. 
Tradicionalmente prevaleceu o ensino da descrição lingüística - eu diria que nem a descrição prevaleceu, mas o exemplário de descrições previamente feitas, pois na escola não se aprendeu a descrever fatos novos, formular hipótese e descrição.O que se aprende, na verdade, é exemplicar descrições previamente feitas pela gramática. Mais modernamente, as descrições tradicionais foram substituídas por descrições da teoria da comunicação, e hoje o aluno sabe o que é emissor, receptor, mensagem, etc. Na verdade se substituiu uma metalinguagem por outra!

Tanto para a sociolingüística como para a psicolingüística encara a diversidade não como um problema, mas como uma qualidade constitutiva do fenômeno linguístico e é nesse sentido que qualquer tentativa de buscar apreender apenas o invariável, se valer de oposições como "língua e fala", ou seja, uma redução na compreensão do fenômeno linguístico.

\section{1- A utilização da leitura e escrita na língua materna como uma tarefa multidisciplinar}

Há uma grande questão no tratamento com a diversidade lingüística no processo de aquisição das formas de expressão escrita que é defini uma política capaz de assegurar eficiência no domínio dos meios de expressão lingüística num contexto sociocultural tão heterogêneo quanto o brasileiro. Mas uma política com esse perfil só será de fato democrática para duas coisas: 1) Buscar e adquirir o conhecimento, por conta própria, em toda a variedade de fontes, principalmente as escritas, 2) expressar com clareza e desenvoltura oralmente e por escrito as informações, os conhecimentos e as idéias que por ventura queiram comunicar a outras pessoas.

É importante um trabalhar multidisciplinar para o ensino da língua materna, mas argumentamos ainda no diz respeito a pedagogia da língua baseada na depreciação lingüística e sociocultural do aprendiz que gera insegurança, angustia a auto-estima e só produz silêncio. Este é um discurso corrente de textos contemporâneos sobre ensino de língua materna. A língua, no entanto, é objeto privilegiado nessas discussões porque é o meio coletivo básico e por assim dizer universal de expressão.

Durante algum tempo acreditou-se que a salvação do ensino da língua se encontrava no respeito à diversidade de seus usos e no refinamento método de análise de sua estrutura, mas só há acesso se for baseado em um olhar científico sobre a língua, compreensão do 
sentido sociocultural dos seus usos e rigor quanto aos conceitos gramaticais. Seria desnecessário registrar que tudo isto reflete a importância assumida pela linguística na formação do professor de língua e na elaboração do material e das estratégias de ensino.

A língua materna é por excelência da educação e da cultura, a disciplina. Supera a todas as demais, porque é o instrumento único de expressão e comunicação, alguns a utilizam para expressar o pensamento de uma elite preocupada com a unidade e correção da língua culta; a maioria, a despeito das particularidades lingüísticas que os diferenciam regional e socioculturalmente, tem direito ao domínio da expressões que dão acesso aos bens da cultura do país em toda plenitude.

Consolida-se hoje uma antiga certeza, que havia inspirado os bons professores do passado: a língua é uma forma de conhecimento, expressão e compreensão, mas não existe por si mesma,como um objeto de adoração e culto. Quando se diz que uma pessoas conhece uma língua, o que se diz, antes de qualquer coisa, é que ele é capaz de comunicar-se nessa língua.

$\mathrm{Na}$ tradição escolar brasileira, tem resignado duas competências consideradas complementares: o domínio da variedade da língua materna/padrão e a aptidão de " saber falar e escrever corretamente" para identificar a sua construção e processos estruturais.

É inegável que a escola tradicional alcançar razoável na busca desses objetivos, mas isso tem uma explicação; esses estudantes já eram usuários da língua que iam aprender a escrever e analisar. Mas amplo, esse quadro tem mudado muito e vem motivando lingüísticas e professores da língua materna a debater sobre uma nova política de ensino da língua.

A leitura e a escrita, ainda hoje, são um dos pontos frágeis na educação, deparamos com inúmeros equívocos no que se refere a quem cabe o ofício de se ensinar a ler e escrever.

A prática constante de leitura e escrita devem ser incorporadas pela escola como meta primordial envolvendo todas as áreas do conhecimento, uma vez que são habilidades indispensáveis, para a formação do educando.

É dever da escola oportunizar ao aluno condições de se apropriarem de conhecimentos historicamente constituídos, de se sentirem construtores a produtores desses conhecimentos e de bons textos; é tarefa de todas as áreas, mediarem o trabalho de leitura e escrita, cada qual em suas especificidades. Cabe a cada disciplina atuar nesse trabalho de forma criativa argumentativa, reflexiva e, acima de tudo, crítica porque a reflexão de tudo que vemos, ouvimos e lemos deverá ser expressa por escrito. A leitura e a escrita devem ser incentivadas dentro da sala de aula, independente, da área a ser trabalhada, orientada pelo professor. É tarefa árdua pelo fato de que nossos alunos não possuem o hábito da leitura, pois 
na maioria das vezes o único contato com a leitura é na escola, a família pouco contribui ou, em muitas vezes, nada contribuem em favor do despertar dos seus filhos ao mundo da leitura e da escrita. Dessa forma, a escola tenta realizar um trabalho focado na leitura e escrita, o que não é nada fácil.

Percebemos em nossa prática pedagógica que vivemos rodeados de variações linguísticas e que na oralidade as crianças se entendem se comunicam sem nenhum pudor, porém, ao escrever deverá se portar na escrita em uma linguagem formal muito diferente da oralidade. As pesquisas nos mostram que falamos uma língua e temos de aprender a ler e escrever em outra língua.

Os estudos de nossa língua falada levada a efeito por vários pesquisadores, entre eles um grande grupo de linguístas de todo Brasil reunidos no Projeto de Gramática de Português falado, estão mostrando não só que há uma grande variação linguística (geográfica e social) interna no País-Ao contrário do que sempre disse o mito da unidade lingüística brasileiramas também que a língua que falamos difere muito da língua falada em Portugal, a qual deu origem ao português escrito. Na verdade, hoje podemos dizer que falamos uma língua e temos de aprender a ler e escrever em outra língua.

A prática pedagógica nos conduziu a uma reflexão sobre o ato de ler e escrever cabe a quem essa função? Muitas passagens onde sempre ouvia do professor de matemática, história e outras disciplinas, que não lhes cabia a função de corrigir e ou solicitar produções de textos e leituras dos seus alunos. Limitavam-se, apenas, a solicitar respostas copiadas dos livros didáticos. O que percebemos, hoje, é que esse paradoxo está sendo revisto e repensado por parte de muitos educadores e estudiosos do assunto que focam esses questões como tarefa e obrigação de todas as áreas, que leitura e escrita é "dever da escola". E, de vagarinho todas as áreas estão começando a desempenhar esse papel de formador de bons leitores e bons escritores.

A escola é o único veiculo mediador do processo ensino aprendizagem dessas variações linguísticas tão complicadas na visão dos educandos. Tomam-se uma constante as indagações sobre o ler e escrever corretamente o nosso português, só vamos ser escritores competentes se praticarmos a leitura de diferentes textos e interagindo com atas de forma crítico- reflexiva e argumentativa. A escola é o único local onde efetivamente se aprende a ler e escrever.

Cabe então o oficio a todos os professores de todas as áreas, a responsabilidade de mediar o trabalho de leitura e escrita cada qual nas suas especificidade, incentivando nossos educandos a produzirem textos com coerência e coesão, opinando, argumentando, criticando e 
/ou analisando cada assunto da forma prazerosa e eficiente. Ler tudo, desde as banalidades até as coisas que o professor julgar que devem ser lidas para o desenvolvimento pessoal do aluno como pessoa sensível civilizada, culta, como cidadão para o estabelecimento de seu senso estético de sua solidariedade humana, do seu conhecimento.

É tarefa e responsabilidade de todas as áreas A tortura e a escrita devem ser incentivadas dentro da sala de aula, orientada pelo professor. Este deve oportunizar a vivência e o encantamento da descoberta dos muitos sentidos de um texto. Na escrita o incentivo deva ser o mesmo, proporcionando aos alunos oportunidades para que escrevam da forma significativa aos leitores a quem querem informar, convencer. persuadir ou comover. Acabarão por descobrir que produzir texto não é uma tarefa tão penosa quanto parece.

Não basta ensinar os conteúdos de língua portuguesa desvinculados das demais disciplinas, ê necessário fazê-lo de forma interdisciplinar associando-os as demais áreas do conhecimento. É necessário promover o diálogo interdisciplinar, se quisermos que o aluno adquira a visão do todo. É necessário transformar a sala de aula em um espaço no qual se discutam as problemáticas socais, atuais e urgentes, as relações interpessoais e os valores que as norteiam.

É imprescindível que façamos de nossas salas de aula a primeira ponte para as atividades de leitura e escrita independente da área a ser trabalhada.

O despertar do prazer de atribuir sentido a um texto, cada qual em sua área num trabalho multidisciplinar e transdisciplinar é tarefa e responsabilidade de todas as disciplinas. Aprender a ler analisar, construir sentidos e significados dentro do conjunto de possibilidades apresentadas pelos textos são habilidades indispensáveis no planejamento de todas as áreas.

Nossos alunos acabarão descobrindo que escrever não é tarefa tão difícil e nem impossível de se realizar, descobrirão que são capazes de escrever e que essa tarefa é tão prazerosa quanto o ato de ler e descobrir o que está nas entrelinhas do texto, a intencionalidade de quem o escreve e que ele próprio pode ser o escritor de sua própria história.

É a ponte que cada professor vai utilizar em sala de aula para realizar árdua tarefa de despertar em cada educando o gosto e o prazer pelo ato de ler e escrever sem a preocupação de apenas corrigir os erros de ortografia ou de concordância, mas orientando-os a reescrita desata textos de forma mais clara e concisa, fazendo-o perceber que o texto escrito por ele é propriedade de todos e todos devem lê-lo;

Todo educador tem o dever e a responsabilidade de mediar o seu trabalho conduzindo seu educando ao hábito da leitura, não pela imposição, e sim pelo prazer da 
descoberta. Na mesma linha. BAGNO (1998) concorda que o Brasil preços de uma política linguística consistente e não de atitudes inspiradas em mitos e superstições sobre a língua. $\mathrm{O}$ autor é incisivo ao afirmar que:

Todas as iniciativas de uma política linguística já existentes desconsideram as reais necessidades dos falantes e centram-se na repressão linguística, pois negam a língua como fenômeno histórico-social, portanto, público e mutável, e como elemento constitutivo da individualidade de cada.

Lembra o autor que do ponto de vista sociolingüístico, obedecemos a diferentes regras, em função das instituições no interior das quais falamos. São consideravelmente diferentes, por exemplo, as exigências das instâncias públicas e das instâncias privadas de fala, seja quanto às regras de uso, ao registro adequado ou ao dialeto que circula nas diferentes instituições.

Contudo, o cumprimento dessas exigências não se dá de forma equilibrada, pois os diferentes dialetos regionais e sociais nem sempre são socialmente aceitos. Nas instâncias públicas de linguagem, particularmente, apenas um falar tem sido admitido, e sua eleição está envolvida em relações de poder, gerando conceitos como variedade padrão, prestígio, forma estigmatizada etc., utilizados tanto por pesquisas linguísticas quanto por estudos sociológicos.

Dessa forma, GERALDI (2000) associa-se a variedades linguísticas não-prestigiosas grupos de falantes que, sociologicamente, não pertencem às classes dominantes, sendo as variedades linguísticas estigmatizadas na mesma proporção da estigmatização social de seus falantes

No livro Preconceito linguístico: o que é, como se faz, BAGNO (1998) enfatiza que "só existe língua se houver seres humanos que a falem". Como o ser humano é, segundo Aristóteles, um "animal político", não é possível tratar de língua sem tratar de política. O autor atribui o preconceito linguístico ao reflexo na língua das diferenças sócio-políticoculturais entre os indivíduos, muitos dos quais são igualmente discriminados socialmente. A confusão entre língua e gramática normativa, que impõe um padrão como a língua "correia" e discrimina qualquer outra variedade, encarrega-se de complementar esse quadro.

Bagno aborda os chamados mitos linguísticos, rebatendo, inicialmente, a idéia de que "a língua falada no Brasil apresenta uma unidade surpreendente", decorrente do preconceito irreal de "unidade linguística no Brasil". Esse mito é prejudicial à educação, pois, ao não reconhecer a diversidade do português falado no país, a escola tenta impor sua norma 
linguística a todos os brasileiros, independentemente de idade, raça, situação socioeconômica e grau de escolaridade. Ignora, portanto, que o português apresenta um alto grau de variabilidade devido não só à grande extensão territorial, mas à injustiça social, que coloca o Brasil como o segundo país com a pior distribuição de renda. Essa diferença no status social dos brasileiros aumenta o abismo linguístico entre os falantes da variedade não-padrão (que constituem a maioria dos usuários da língua) e os falantes da "suposta" norma culta, ensinada pela escola. Como poucos indivíduos têm acesso à educação formal, muitos permanecem à margem do domínio da variedade culta, deixando de usufruir de diversos serviços a que teriam direito, não apenas, mas também por não compreenderem a linguagem empregada pelos órgãos públicos.

Embora a variedade não-padrão também apresente uma gramática particular, regida por regras específicas, e atenda às necessidades comunicativas dos falantes, ela não é considerada como válida, mas desprestigiada e ridicularizada. Isso porque uma variedade linguística 'vale' o que 'valem' na sociedade os seus falantes, isto é, vale como reflexo do poder e da autoridade que eles têm nas relações econômicas e sociais.

Tendências unificadoras que geram as chamadas normas "padrões são comuns a todas as línguas, o que leva ao estabelecimento, nas comunidades linguísticas de falantes, de forças bastante contraditórias: algumas puxando para a diferenciação e outras para um certo ideal de unidade. Historicamente, conforme lembra o autor, a complexidade da natureza desse quadro foi primeiramente identificada pelos gregos alexandrinos, que percebiam a diferença entre o grego clássico, encontrado nos textos dos autores consagrados, e a modalidade de grego que falavam. Essa diferença era acentuada pela grande distância temporal que os separava. Da mesma forma, percebiam a diversidade entre os vários dialetos do grego falado na época e a chamada koiné, dialeto ático tornado língua comum na expansão do império de Alexandre. Diante de toda essa diversidade, eles priorizaram o estabelecimento e o cultivo de um ideal de língua, segundo o padrão de linguagem encontrado nos grandes escritores. Em decorrência desse processo, os gregos alexandrinos criaram a gramática como disciplina intelectual autônoma, voltada para o estudo da língua, com o objetivo principal de fixar padrões de correção. Figura de destaque nesse contexto foi Dionísio da Trácia, intelectual alexandrino reconhecido pêlos historiadores como o autor da primeira gramática, que definiu seu trabalho como o estudo empírico dos usos normais dos poetas e prosadores, modelos de correção gramatical.

Instituiu-se, assim, a noção de correção linguística, que ainda povoa o imaginário dos falantes com o modelo de língua ideal, baseado na linguagem dos grandes escritores. $\mathrm{O}$ 
critério que estabelece a correção assenta-se em valores que, por razões políticas e/ou culturais, são agregados a certas formas e não a outras. 


\section{3 - A PRÁTICA DE REFLEXÃO SOBRE O LUGAR DO TEXTO E DA GRAMÁTICA NA SALA DE AULA NAS PRÁTICAS LINGUISTICAS}

Diversos pesquisadores da área lingüística aplicada vem se dedicando a trazer sugestões de como efetivar, na prática, as opções teóricas assumidas pelos PCNs. Dentre tais, a noção de gêneros discursivos é a que tem recebido maior atenção. Certamente, isso se deve porque, como lembra BARBOSA (2000):

A noção de gênero permite incorporar elementos da ordem do social e do histórico; permite ainda considerar a situação de produção de um dado discurso Nesse sentido, a apropriação de um determinado gênero passa, necessariamente, pela vinculação deste com seu contexto socio-histórico-cultural de circulação .

De acordo com os PCNs, tomar o texto como "a unidade básica do ensino" possibilitaria a discussão/ produção de textos de maneira a dar espaço às diferentes vozes que emergem em uma sala de aula, entendidas como representativas de realidades socio-históricas distintas e que, portanto, devem ser vistas e respeitadas como tais. Ainda, ao optar por essa forma de tratamento dos textos, os educadores estariam assumindo a idéia de que eles não seguem padrões fechados, que só permitem uma interpretação, e sim que há uma variedade de leituras possíveis que se constroem na co-interação leitor-texto.

Nessa perspectiva, portanto, deveria fazer parte do ensino e aprendizagem da língua portuguesa, a reflexão sobre a linguagem. Como indicam os PCNs:

\footnotetext{
Tomando-se a linguagem como atividade discursiva, o texto como unidade de ensino e a noção de gramática como relativa ao conhecimento que o falante tem de sua linguagem, as atividades curriculares em Língua Portuguesa correspondem, principalmente, a atividades discursivas: uma prática constante de escuta de textos orais e leitura de textos escritos e de produção de textos orais e escritos, que devem permitir, por meio da análise e reflexão sobre os múltiplos aspectos envolvidos, a expansão e construção de instrumentos que permitam ao aluno, progressivamente, ampliar sua competência discursiva.
}

Em linha s gerais, para ampliar essa competência discursiva, os PCNs sugerem um movimento um movimento metodológico que vai da AÇÃO à REFLEXÃO que, por sua vez, desencadeia novamente a AÇÃO, o que permite incorporar a reflexão nas atividades lingüísticas com os alunos. Essa proposta possibilita colocarem-se em prática os objetivos de 
ensino a escola deverá organizar um conjunto de atividades que possibilitem ao aluno desenvolver o domínio da expressão oral e escrita em situações de uso público da linguagem, levando em conta a situação de produção social e material do texto.

Consideradas essas diretrizes, torna-se fundamental definir o que está abrigado, nos PCNs, sob os termos genéricos conteúdos e práticas. Nesse documento, os conteúdos se dividem em conceitual e procedimental e são referentes às práticas de linguagem que, por sua vez, se distinguem entre práticas de escuta de textos orais, de leitura de textos escritos, produções de textos orais e escritos e prática de análise lingüística. Há ainda os conteúdos sobre o desenvolvimento de valores e atitudes, que permeiam todo o trabalho escolar

O que se percebe, então, é que não se encontra nos PCNs uma lista propriamente dita de tópicos gramaticais a serem trabalhados em cada ciclo e, sim, alguns aspectos lingüísticos que podem ser explorados conjuntamente ao trabalho com textos. Como sugestão, há a indicação de alguns "gêneros privilegiados" para os terceiro e quarto ciclos, que serviriam de base para a construção do programa de ensino. Quanto a isso, cabe lembrar:

[...] o professor, ao planejar sua ação, precisa considerar de que modo as capacidades pretendidas para os alunos ao final do ensino fundamental são traduzidas em objetivos no interior do projeto educativo da escola. São essas finalidades que devem orientar a seleção dos conteúdos e o tratamento didático que estes receberão nas práticas educativas (PCNs,).

Pois bem, a partir das considerações acima, cabe formular mais claramente nosso objetivo neste trabalho. Ele diz respeito à prática de análise lingüística, portanto, a uma das "possibilidades" de prática antes referida. Mais especificamente, nossa intenção é formular uma reflexão sobre como podem ser vistos os conteúdos gramaticais em contexto de ensinoaprendizagem de língua materna, quando se toma por base o referencial enunciativo, em o qual, acreditamos, está em consonância com o que sugerem os PCNs.

Para tanto, partimos da problematização da questão do ensino de gramática em sala de aula, tendo em vista o aporte enunciativo, para então sugerir uma atividade que propicie a reflexão lingüística dos alunos, a fim de desenvolver sua capacidade discursiva. Dentro do movimento metodológico acima apresentado, nossa discussão se centrará na REFLEXÃO, sem, contudo, deixar de considerar as AÇÕES envolvidas no processo de aprendizagem. Por fim, optamos por voltar nossa proposta aos professores dos terceiros e quartos ciclos do ensino fundamental, procurando colocar em prática os parâmetros indicados para esses níveis. 
Entendemos que há a tentativa de um deslocamento entre a tradicional aula de português, que, por não considerar a reflexão sobre a linguagem, visa apenas ao ensino de normas gramaticais, e a prática pedagógica inclusiva, que busca, através das discussões acerca da linguagem (suas funções, suas práticas), construir um aluno-sujeito que consiga deslizar entre os registros de língua, que entenda e respeite as variedades, que leia os pressupostos e não-ditos, que faça coisas no mundo através da linguagem, enfim, que seja um verdadeiro cidadão.

Cabe, porém, cabe discutir o lugar que os aspectos gramaticais têm numa aula de língua materna concebida a partir do que formula os PCNs.

Houve um tempo,6 em que a gramática - entenda- se o termo como sinônimo de normatização lingüística - era a única possibilidade de ensino da língua portuguesa para o professor em sala de aula.

Hoje em dia, tudo mudou: há maior acesso à informação, os livros circulam com mais facilidade e a lingüística já disse a que veio. Então, seria de se supor que não teríamos mais problemas com o ensino de língua portuguesa. No entanto, esse otimismo não se configura numa realidade para aqueles que ensinam e isso se deve a, pelo menos, dois aspectos da questão que devem ser considerados. De um lado, há ainda muita confusão decorrente dos anos de críticas mais acirradas à gramática - sobre que prática lingüística desenvolver; de outro lado, há dúvida, por parte dos professores, sobre o que querem dizer os especialistas quando afirmam que a língua deve ser ensinada a partir do texto e/ou do uso da linguagem.

Quanto ao primeiro aspecto, cabe ver que as relações entre texto/gramática/escola precisam receber tratamento diferenciado especialmente em função da necessidade de se vincular ao texto a discussão em torno da questão gramatical na escola. Isso tem significativa importância, neste contexto, porque, geralmente, é dito ao professor de língua materna que deve ser priorizado o ensino da modalidade textual, deixando para um segundo momento aspectos relativos à gramática da língua. Ora, se tomarmos como base o que sugerem os PCNs, veremos que os tais aspectos gramaticais precisam ser levados em conta, na dimensão de uso da linguagem. A questão que resta, porém, é ainda: é possível tratar a gramática como algo que esteja integrado ao texto e não como um adendo?

Quanto ao segundo aspecto, cabe ilustrá-lo com um exemplo: chama a atenção o fato de poucos professores conhecerem com alguma profundidade uma gramática que se propõe, exatamente, a abordar o uso lingüístico, trata-se da Gramática de usos do português, de Maria Helena de Moura Neves, em circulação desde 2000. Evidentemente, muitos professores a 
conhecem se tomarmos, neste contexto, conhecer no sentido de "ter visto" ou mesmo de "ter adquirido".

Nosso questionamento, no entanto, vai em outra direção: acreditamos que os professores que "conhecem" a gramática não a leram e se a leram não a entenderam. Se, como diz a autora na introdução da gramática. Conforme NEVES, (2000).

A meta final, no exame, é buscar resultados de sentido partindo do princípio de que é no uso que os diferentes itens assumem seu significado e definem sua função, e de que as entidades da língua têm de ser avaliadas em conformidade com o nivel em que ocorrem, definindo-se, afinal, na sua relação com o texto.

Então, cabe perguntar por que os professores não recorrem à gramática para falar de uso lingüístico em sala de aula?

Em resposta a esse questionamento, talvez não seja precipitado dizer que os professores não possuem, hoje, os instrumentos necessários para ler esta e outras obras da atualidade. A falta - que pode ser atribuída a fatores sociais, políticos e mesmo salariais - tem conduzido uma massa de professores à repetição de um clamor - como abordar gramática, texto e uso integradamente?

Enfim, nesta pequena retrospectiva, é possível ver que a busca de uma prática de linguagem em contexto de ensino de língua materna, considerando os PCNs, coloca em destaque muito mais do que simples questões metodológicas. Na verdade, o que percebemos é uma intrincada rede de questões que dizem respeito a múltiplos aspectos: teóricos, metodológicos, conceituais, sociais e até econômicos.

Assim, se o trabalho com a prática de análise lingüística não pode prescindir do uso lingüístico em sua modalidade de texto, então, certamente, um exercício de reflexão acerca da relação prática de análise lingüística/ uso lingüístico, por mais incipiente que ele seja, deve considerar a linguagem no âmbito social do qual ela faz parte. Âmbito este que inclui, além da própria ordem lingüística, os sujeitos que interagem, as situações de interação, os objetivos da interação, dentre outras. 


\section{4-ABORDAGEM DIDÁTICO-PEDAGÓGICA QUANTO ÀS SEMELHANÇAS E DIFERENÇAS NO PROCESSO DE ENSINO -APRENDIZAGEM DA LÍNGUA MATERNA}

A maioria dos alunos gosta de participar de atividades que envolvem a oralidade. Todavia, há aqueles que preferem isolar-se e permanecer no habitual mutismo,quando se trata de expor a um público maior o que pensam ou sentem.

É possível que o limitado envolvimento de alguns alunos nos atos de fala se deve a situações escolares por eles vivenciadas, já que em algumas escolas ainda se mantém uma estrutura seletiva que valoriza os alunos cujo grupo social usa a chamada língua culta. Assim, quando se assume a lingüística como forma de interação entre pessoas históricas, geográficas e socialmente situadas, não há como desconsiderar os muitos dialetos ou variedades lingüísticas que identificam os indivíduos que interagem verbalmente.

Enquanto atividade humana, a língua materna tem uma dimensão histórica e social que atribui a ela diferentes funções.

É através dos gêneros textuais-amplamente explorado na escola- que permite ao aluno tanto a descoberta das relações sonoro-gráficas como as possibilidades combinatórias das unidades lingüísticas e, de modo especial, representam um grande estímulo à expressão verbal oral e escrita.

Se consideramos a ação pedagógica da escola como parte da política do planejamento lingüístico, poderemos concluir que a influencia da escola na língua não deve ser procurada no dialeto vernáculo dos falantes, mas sim, em seus estilos formais monitorados.

A pergunta que deveríamos fazer, então, não é somente se as escolas são veículos eficientes de transmissão da língua materna, mas especificamente, se as escolas contribuem para que os alunos adquiram os estilos formais da língua.

Para responder a essa pergunta, a pesquisa de sociolingüística educacional precisa concentrar-se na língua usada em sala de aula. Apesar que nossa atenção não deve se restringir à língua materna da escola.è necessário também explorar como a conversa, as práticas de aquisição da língua e os processos intelectuais se influenciam mutuamente em sala de aula e quais as implicações para a educação. 
Atentamos para um tópico relacionado as semelhanças e diferenças bastante discutida: o uso de variedades não-padrão em sala de aula, recomendados em recentes pesquisas como uma estratégia de transição, porém, tem sido criticada, pois argumentam que o uso demasiado do dialeto retarda o contato dos alunos com a língua padrão e contribui para o declínio dos padrões educacionais.

Não nos aprofundaremos nesta discussão porque a posição que assumimos é que tanto língua padrão quanto o dialeto serão usados em sala de aula, cumprindo funções diferenciadas.

Todo o processo de ensino-aprendizagem da língua com a aquisição e uso da língua materna, observando e atribuindo sentido as situações de uso. Com efeito, o conhecimento da língua é algo cumulativo, que se expande à medida que o objeto em ela se corporifica, se multiplica e diversifica.

Entendemos que as estratégias intuitivas usadas pelos professores para lidar com a complexa questão da variação lingüística podem contribuir para a implementação de uma pedagogia culturalmente sensível. Os alunos devem sentir-se livres para falar em sala de aula e deve ser ratificado como um participante legítimo da interação, onde o professor poderá justapor a variantes, permitindo assim, que se desenvolva a consciência do aluno sobre a aquisição da língua materna, enquanto variação lingüística. 


\section{CONSIDERAÇÕES FINAIS}

Vale ressaltar, para finalizar, que a situação LA com relação à chamada pesquisa básica ou teórica, que abordamos ligeiramente no início, corresponde aproximadamente à mesma relação entre LA e professores: a estes parece caber a tarefa de "aplicar", ou seja, colocar em prática, na sala de aula a metodologia que os linguistas aplicados defendem, a partir de pesquisas, muitas vezes empíricas, é bem verdade, mas sempre em condições que nunca ou raramente correspondem às reais situações de sala de aula, tão diversificadas quanto forem os países, as regiões, os grupos. Ainda que defendamos a existência de regularidades que fazem da sala de aula uma formação discursiva onde se manifestam relações de poder, é também em nome do conceito mesmo de formação discursiva que se defende a diversidade, o diferente, a presença constante da resistência. Dizer o que se deve fazer é, no mínimo, fazer tabula rasa das diferenças; é acreditar que a verdade se encontra em alguém ou em algum lugar e que é preciso lutar para atingi-la, tentando por em prática o que nos é ensinado. Se é difícil, ou talvez impossível, escapar a essa tendência teleológica, é, no entanto, possível buscar questioná-la para minimizar seus efeitos castradores e avassaladores.

Por outro lado, podemos concluir que, à revelia do consciente, o quê aqui apresentam apontamos para a complexidade da relação teoria-prática, mas não uma complexidade meramente cognitiva. Para entendermos melhor o que isso significa, é preciso lembrar que toda teoria, enquanto abstração, é também interpretação e que toda "prática" já é por si só interpretação. Ora, interpretar é um ato que não se encontra sob o controle total (consciente) do interpretante, mas depende da sua historicidade, dos valores, crenças (socialmente partilhadas), experiências de toda sorte (afetivas, sociais, intelectuais); enfim, é a vida do sujeito-interpretante que determina a sua maneira de ser, de ver, de perceber, de sentir, de se relacionar e de pensar.

Uma vez entendido isso, fica fácil percebe- que não é possível imputar a toda aprendizagem ou reflexão teórica uma mudança radical de comportamento, na exata medida da proposta teórica ou das soluções trazidas pêlos linguístas aplicados e pedagogos. O (a) professor (a) pode ter assimilado teoricamente os princípios de uma determinada metodologia e, na prática, proceder segundo sua experiência ou suas crenças, ainda que inconscientemente; ou ainda, e é o que parece mais normal, proceder de acordo com uma mistura de fragmentos teóricos resgatados aqui e lá (e não teorias completas e coerentes) que lhe chegam através de 
leituras ou de cursos de formação continuada e se modificam ao se cruzarem, inevitavelmente, entre si e com as crenças e experiências cotidianas que caracterizam sua prática.

Tal responsabilidade, aliás, não recai sobre ninguém em particular: fruto do momento social e histórico em que vive, o sujeito, cindido, fragmentado, sofre a ação do seu inconsciente, fazendo aflorar, à revelia do seu consciente, desejos, recalques, de maneira que jamais poderá ter o controle absoluto sobre o que diz, sobre o que faz, o que pensa, mesmo que ilusoriamente o desejem pedagogos, lingüistas aplicados, autoridades responsáveis pela educação. E bastante ilustrativa, a respeito do inconsciente e do desejo recalcado, desejo de transparência da linguagem, quer dizer que para cada um, qualquer que seja sua história linguística, o inconsciente será sempre interpretado como se houvesse uma língua original que tivesse permitido esta transparência perfeita, ou seja, a articulação do desejo, mas que algum acidente produziu um impedimento. A partir de então, esta língua tornou-se a língua de um sujeito acometido de mudez quanto à expressão do desejo, e este desejo não pode mais se exprimir a não ser pelos acidentes e caprichos. Pois bem, ao mesmo tempo essa "Grundsprache" torna-se também a língua de um pai, aquele mesmo pai que procedeu a este interdito, o desejo se reclamando necessariamente dele, de um pai condenado à mudez.

Queremos com estas reflexões defender a idéia de que não é possível explicar as relações entre teoria e prática, sem considerar o sujeito e sua constituição psicanalítica e social, como parecem fazer as ciências, na ânsia da objetividade. A busca da transparência, que se manifestaria no controle da aprendizagem e, portanto, num primeiro momento, na tão desejada assimilação perfeita ou ideal dos ensinamentos teóricos, e, num segundo momento, na transformação dessa assimilação em atos (prática), coincide com a busca de uma verdade que, ao mesmo tempo em que transcende ao próprio homem, só é possível ser atingida a partir da razão, do logos, capaz de controlar a diversidade para chegar à generalização. Se, entretanto, considerarmos o sujeito inconsciente, disperso e heterogêneo, chegaremos à conclusão de que tal maneira de ver as relações entre teoria e prática, entre problema e solução e, portanto, a própria aprendizagem, é, como já afirmamos na primeira parte deste trabalho, simplória e simplista pois, ainda que as pesquisas acreditem partir da observação da sala de aula, a realidade será sempre interpretada e as soluções, além de idealizadas, são, de certa maneira, impostas ao professor que, ilusoriamente, acredita por em prática o que lhe foi ensinado.

Portanto, o debate entre a questão da diversidade lingüística e o papel assumido pela escola, em referência ao ensino da Língua Portuguesa, tem sido constantemente retomado por lingüistas e educadores. O reconhecimento da legitimidade das normas populares, como 
instrumento de comunicação de afirmação de identidades sociais, tem sido amplamente divulgado, porém a prática pedagógica ainda permanece alicerçada no ensino da norma padrão, desvalorizando os vários dialetos de menor prestígio. Este trabalho convida os educadores, principalmente aqueles não lingüistas, a criar círculos de educadores/aprendizes, no sentido de repensar o problema e de redefinir as atividades em sala de aula, com projetos de ensino que garantam a inclusão das variantes lingüísticas como objeto de afirmação/expansão do universo cultural do aluno. 


\section{REFERÊNCIAS}

BAGNO, M. Preconceito Linguístico: O que é, como se faz. São Paulo: Loyola, 1998.

, Marcos; GAGNÉ, Gilles \& STUBBS, Michael. Língua materna: letramento, variação e ensino. São Paulo: Parábola, 2002.

BAKHTIN, Mikhail. Estética da criação verbal. São Paulo: Martins Fontes, 1992.

BECHARA, Evanildo. Ensino de gramática: Opressão ou liberdade? $11^{\mathrm{a}}$ ed. São Paulo:Ática, 2002.

BRASIL. MEC. SECRETARIA DE EDUCAÇÃO FUNDAMENTAL. Parâmetros Curriculares Nacionais: Língua Portuguesa. Brasília, 1997.

FIORIN, Jose Luiz. Introdução ao pensamento de Bakhtim. São Paulo: Atica ,2006

GERALDI, C. FIORENTINI, D; PEREIRA, E (org.) Cartografias do Trabalho Docente. Campinas, SP. ALB: Mercado das Letras, 2000.

(1984),

.Prática de Produção de Textos na Escola. Trabalhos em Lingüística Aplicada.

LUFT. C P . Língua \& Liberdade: Por uma nova concepção da língua materna. Porto Alegre, L\&PM, 1995. (Coleção Universidade Livre).

MILANEZ, W. Pedagogia do Oral: Condições e Perspectivas para sua aplicação no Português. São Paulo: Sarna Editora, 1993.

NEVES, M. H. M.. Gramática na Escola. São Paulo: Contexto, 2000.

PARÂMETROS curriculares nacionais de língua portuguesa. Terceiro e quarto ciclos do ensino fundamental.

Disponível em: <http://mecsrv04.mec.gov.br/sef/estrut2/pcn/pdf/ portugues.pdf.: acesso em julho de 2008 .

PEREIRA, Maria Teresa Gonçalves. O professor de língua portuguesa: modos de ensinar e de aprender. In: AZEREDO, José Carlos de (org). Língua portuguesa em debate conhecimento e ensino. Petrópolis: Vozes, 2000. 
